\title{
OMISSÃO DE SUJEITO PRONOMINAL ANAFÓRICO E AS CONSTRUÇÕES DE DUPLA NEGAÇÃO
}

\author{
ANAPHORIC NULL SUBJECT AND DOUBLE \\ NEGATIVE CONSTRUCTIONS
}

\author{
GABRIEL DE ÁVILA OTHERO ${ }^{1}$ \\ MARCOS GOLDNADEL ${ }^{2}$
}

\begin{abstract}
RESUMO: Neste artigo, investigamos omissão e a expressão de sujeitos expressos pronominais e nulos em construções de dupla negação em português brasileiro. Para isso, analisamos um corpus de língua falada da região Sul do Brasil, o corpus VARSUL. Apesar de a literatura apontar para o fato de que o PB tem privilegiado orações com sujeito pronominal expresso em detrimento de sujeito nulo (cf. Duarte 2012, entre outros), percebemos que as construções de dupla negação, ao contrário da expectativa, favorecem o sujeito nulo. Acreditamos que tal construção favoreça o sujeito nulo porque veicula conteúdos ativados (que, por princípio, podem ser ocultados da superfície da frase). Além desse fator pragmático, investigamos também a relação desses efeitos com um fator semântico que favorece a retomada por sujeito pronominal expresso: o traço de gênero semântico do referente. Analisamos cenários de confluência e conflito entre esses princípios de natureza gramatical distinta distintos e o que encontramos na análise do corpus corrobora empiricamente nossas previsões teóricas.

Palavras-chave: construções de dupla negação; sujeito nulo; sujeito pronominal expresso.
\end{abstract}

\begin{abstract}
In this article, we investigate null and overt pronominal subjects in double negation clauses in Brazilian Portuguese. In order to do so, we investigate a spoken language corpus from the southern region of Brazil, the VARSUL corpus. Although the literature points to the fact that BP privileges clauses with overt pronominal subject, instead of using null subject (cf. Duarte 2012, among others), we noticed that double negation clauses favor null subject. We believe such clauses favor null subjects because they convey activated contents (which, in principle, can be covert in the surface of the sentence. In addition, we investigate the relation of these effects with a semantic factor that favors overt pronominal subject: the semantic gender of the referentlantecedent. We analyzed scenarios of confluence and conflict between these distinct grammatical principles and we found empirical arguments in the analysis of the corpus that corroborate our theoretical predictions.
\end{abstract}

Keywords: double negatives; null subject; overt pronominal subject.

\footnotetext{
${ }^{1}$ Universidade Federal do Rio Grande do Sul (UFRGS), Porto Alegre, RS, Brasil. gabriel. othero@ufrgs.br

Orcid: https://orcid.org/0000-0002-2060-6312

${ }^{2}$ Universidade Federal do Rio Grande do Sul (UFRGS), Porto Alegre, RS, Brasil. emegold@, gmail.com

Orcid: https://orcid.org/0000-0002-2796-8623
} 


\section{INTRODUÇÃO}

Os fenômenos de dupla negação (ver exemplos 1 e $2^{3}$ ) começaram a ser estudados na região Sul do país por Goldnadel et al. (2013) e Lima (2013), com base em arquivos de entrevistas sociolinguísticas do projeto VARSUL ${ }^{4}$.

(1) Eu estou achando que ele não vai aguentar a ponta não.

(2) Não, não me obrigou não. Fui por livre e espontânea vontade.

Os estudos realizados com base nos dados da Região Sul encontrados nas entrevistas do Projeto VARSUL (cf. Goldnadel et al 2013, Lima 2013, Goldnadel 2016, Nunes 2016, Goldnadel \& Petry 2017) receberam, até agora, apenas análises de cunho pragmático-discursivo. Tendo em vista a constatação de que a região investigada, no início da década de 1990, encontrava-se em um estágio inicial de implementação da nova forma de negação sentencial, os estudos mencionados dedicaram-se a verificar (em consonância com uma tendência nos estudos sobre o Ciclo de Jespersen) qual seria a motivação pragmática para a adoção, por parte dos falantes, de uma estrutura alternativa de negação. Na análise dos enunciados de dupla negação encontrados no corpus, os três estudos indicaram forte motivação pragmática para o uso de negação sentencial não canônica5 .

Agora, temos interesse em explorar uma propriedade gramatical dessas construções que se situa na interface sintaxe x semânticalpragmática, a saber, a realização de sujeitos preenchidos (exemplo 1) ou nulos (exemplo 2) em estruturas de dupla negação. A ideia básica que exploraremos aqui é a seguinte: enunciados de dupla negação, por suas características pragmáticas favorecem o apagamento do sujeito.

(3) É, mas aqui [o lugar $]_{\mathrm{i}}$ é bom, não é? $\emptyset_{\mathrm{i}}$ Não é ruim não.

Para tentar provar nosso ponto, elaboramos quatro hipóteses de trabalho que serão apresentadas e detalhadas na seção 3. Investigaremos aqui, como mencionamos, ocorrências de dupla de negação em um corpus de fala transcrita. São 36 entrevistas orais com dados de fala das cidades de Curitiba (PR), Florianópolis (SC) e Porto Alegre (RS), todas gravadas ao longo da década de

${ }^{3}$ Todos os exemplos foram extraídos do corpus de análise; exceto quando indicarmos o contrário.

${ }^{4} \mathrm{O}$ projeto VARSUL (Variação Linguística na Região Sul do Brasil) busca estudar a língua falada na região Sul do país. É um projeto encabeçado por quatro universidades brasileiras: Universidade Federal do Rio Grande do Sul (UFRGS), Pontifícia Universidade Católica do Rio Grande do Sul (PUCRS), Universidade Federal de Santa Catarina (UFSC) e Universidade Federal do Paraná (UFPR). Para mais informações sobre o VARSUL, remetemos o leitor a Collischonn \& Monaretto (2012) e Bisol \& Monaretto (2016).

${ }^{5}$ Em nenhuma das cidades investigadas nos estudos mencionados (Porto Alegre, Florianópolis e Curitiba) encontrou-se o que a literatura especializada convencionou chamar de NEG 3, i.e. enunciados com o advérbio de negação após o verbo, mais especificamente em fim de frase, como se observa em dados das regiões Nordeste e Sudeste, cf. Camargos (2001), Souza; Lucchesi (2004), Roncarati (1996), Furtado da Cunha $(2001,2007)$. 
1990. Encontramos e analisamos 85 ocorrências de dupla negação, distribuídas entre as três capitais da seguinte maneira: 28 ocorrências na amostra de Curitiba, 30 na de Florianópolis e 27 ocorrências na amostra de Porto Alegre.

Na próxima seção, discutiremos as propriedades pragmáticas das sentenças com dupla negação; na seção 3, trataremos sobre a ocorrência de sujeitos nulos e expressos nas construções de dupla negação e apresentaremos nossas hipóteses de trabalho e os resultados empíricos que encontramos a partir da análise do corpus.

\section{A PRAGMÁtiCA DA DUPLA NEGAÇÃO: UMA EXPLICAÇÃO PARA O FAVORECIMENTO AO APAGAMENTO DE SUJEITO}

Enunciados com dois (ou mais) operadores de negação não são uma exceção na história das línguas. Muitas já passaram pelo que se convencionou chamar de Ciclo de Jespersen, processo que se caracteriza pela mudança no padrão sintático de sentenças negativas, normalmente acompanhada por uma alteração no inventário dos lexemas destinados a realizar a operação semântica de negação sentencial. O caso mais conhecido é o do francês, mas há registro de que o fenômeno tenha ocorrido também em latim, grego, alemão, holandês, galês, árabe, berbere, etc. (cf. Hoeksema, 2009). Além disso, Vossen \& Van der Awera (2014) afirmam haver na Ásia e na Oceania 81 línguas com dupla negação, quatro com tripla negação e uma com negação quádrupla. Em todas essas línguas, houve um estágio em que enunciados negativos apresentaram uma marca redundante de negação, com pelo menos dois lexemas realizando uma única operação semântica. É o que chamamos, então, de dupla negação, i.e. referimo-nos a enunciados negativos em que, apesar da existência de dois lexemas em princípio responsáveis pela operação semântica de negação, apenas uma operação dessa natureza é efetivamente realizada. $\mathrm{Ou}$ seja, trata-se de enunciados em que se observa o que se convencionou chamar de concordância negativa. Não se refere, portanto, aos casos em que um lexema acaba por reverter a operação realizada por outro, produzindo um enunciado semanticamente equivalente a uma afirmação.

Nos casos em que se observa, ao longo da história, uma alteração no padrão da negação sentencial, não há, evidentemente, uma mudança abrupta. Invariavelmente, o que ocorre é que o padrão canônico de negação sentencial passa, em determinado momento, a conviver com um padrão alternativo. A forma alternativa, que surge de modo incipiente, passa, com o tempo, a experimentar um incremento até suplantar a forma original, completando, assim, o ciclo da mudança.

Uma das questões que ocupa a agenda investigativa sobre o ciclo de Jespersen é justamente a que se orienta para a descoberta da razão pela qual uma

${ }^{6}$ Foram selecionadas 12 entrevistas de cada capital, tendo sido considerada na análise uma entrevista para cada tipo de falante a partir da combinação das três variáveis sociais que balizaram a constituição do banco de dados do VARSUL: sexo (masculino ou feminino), idade (menos de 50 anos e mais de 50 anos) e nível de escolaridade (primário, ginásio e científico), cf. Goldnadel \& Petry (2017). 
língua, tendo um padrão estabelecido para a expressão de um aspecto tão central da gramática (a operação de negação), acaba por admitir um padrão alternativo. O próprio Jespersen apresenta uma explicação: para ele, a debilidade fonética característica de operadores de negação, principalmente após processos de erosão ${ }^{7}$, seria a responsável pelo uso de um operador redundante, a fim de garantir a veiculação inequívoca do conteúdo pretendido pelo falante.

Atualmente, a hipótese da debilidade fonética como causa do surgimento de um novo operador rivaliza com outra, segundo a qual a erosão fonética, ao invés de causa, seria a consequência do surgimento prévio de uma segunda marca negativa na sentença. Nessa perspectiva, diante de uma marca nova, a marca original passaria a ser sentida como desnecessária, o que abriria caminho para um enfraquecimento de sua pronúncia, para uma diminuição de material fonético, vindo, nos casos em que o Ciclo de Jespersen se completa, a desaparecer completamente. Ainda nessa linha, o surgimento de um elemento negativo novo, e redundante com o original, teria motivação pragmática (cf. Schwegler 1991, Roncarati 1996, Furtado da Cunha 2001, 2007, Schwenter 2005, 2006, Hoeksema 2009, Van Der Auwera 2009, 2010, Seixas e Alkmin 2013, Goldnadel et al 2013, Larrivée 2010, 2011, Hansen 2009, Dahl 2001, Kiparsky e Condoravdi 2006, Detges e Valtereit 2002). Ou seja, o falante, ao utilizar uma marca redundante de negação, pelo menos nos estágios iniciais de adoção da nova forma de expressão, estaria lançando mão de um recurso formal e expressivo para registrar algum conteúdo de natureza informacional ou discursiva.

A hipótese pragmática é a que, no momento atual, encontra maior número de adeptos (cf. Goldnadel, 2017 para um panorama). E é ela que assumimos aqui. Também é ela que nos permite compreender o motivo pelo qual enunciados com dupla negação favorecem o apagamento do sujeito na oração com dupla negação, como pretendemos demonstrar com dados neste trabalho. Não há, contudo, apenas uma hipótese de natureza pragmática. Embora todos os trabalhos partam de intuições linguísticas similares - ou seja, há uma compreensão compartilhada de um certo efeito pragmático produzido por enunciados com dupla negação que os diferencia de suas contrapartes canônicas -, não há uma forma consensual de determinar teoricamente, de modo mais preciso, o contorno discursivo dessas intuições.

Entre as explicações encontradas para uma função pragmática de enunciados com dupla negação estão a ênfase, a denegação/pressuposição ${ }^{8}$ e a ativação (cf. Goldnadel, 2016, 2017). Assumimos aqui a hipótese de ativação, defendida especialmente em Schwenter (2005, 2006): em linhas gerais, a ideia de que

${ }^{7}$ Sousa (2007), por exemplo, alerta para o fato de a negação pré-verbal em PB poder ser realizada como não, num, nu e até mesmo n'.

${ }^{8} \mathrm{O}$ termo pressuposição é aqui associado ao termo denegação por se tratar de um tipo específico de pressuposição, aquele que Givón (1996) associa a enunciados negativos. Nesse sentido, pressuposição está indissociada da ideia de denegação, conforme se depreende da leitura do próprio Givón. Não se trata, portanto, do conceito clássico de pressuposição, cuja discussão tem longa tradição na Filosofia da Linguagem e na Linguística. $\mathrm{O}$ leitor interessado em compreender melhor a distinção entre pressuposição givoniana e pressuposição clássica encontra uma discussão em Goldnadel (2016). 
enunciados de dupla negação veiculam conteúdo pragmaticamente ativado no discurso. Conteúdo ativado não é o mesmo que conteúdo pressuposto. Pressuposição envolve acordo entre interlocutores sobre determinado conteúdo. Classicamente, desde Stalnaker (1979), um conteúdo pressuposto é um conteúdo mutuamente compartilhado entre os interlocutores". Ou seja, pressuposição tem relação com estados de crença sobre "fatos" e estados de crença sobre as crenças do outro. Já ativação tem relação com o grau de acessibilidade na memória de determinado conteúdo. Um conteúdo que resulta de um proferimento recente que tenha sido aceito pelos interlocutores em uma troca conversacional está pressuposto e ostenta um grau elevado de ativação. Mas um conteúdo pode ser ativado sem ainda poder ser considerado pressuposto. É isso que ocorre, por exemplo, nas perguntas. Quando alguém faz uma pergunta, ativa determinado conteúdo. Contudo, esse mesmo conteúdo não pode ser considerado pressuposto, dado que as condições de sinceridade do ato de fala de perguntar são tais que o enunciador ignora a resposta e supõe que seu interlocutor não a ignore. Ou seja, uma pergunta ativa um conteúdo ainda não pressuposto pelo simples fato de que seu enunciador se apresenta como agnóstico acerca do que foi proferido.

De acordo com Schwenter $(2005,2006)$, enunciados de dupla negação registram que o conteúdo da sentença se encontra ativado no discurso. Essa ativação pode ter sido produzida de modo explícito, ou seja, pelo proferimento do conteúdo em porção prévia da troca conversacional, ou de modo implícito, através, por exemplo, de algum tipo de inferência pragmática durante o ato de fala. Uma questão que surge para ser respondida em defesa da hipótese de ativação seria aquela que indaga por que razão uma estrutura de dupla negação, tal como se apresenta no português brasileiro, se prestaria à marcação de conteúdo ativado. Há uma resposta possível, e ela depende fundamentalmente do conceito de pressuposição.

A literatura pragmática é pródiga em estudos que se dedicam à análise da partição, em enunciados, de conteúdos novos e velhos. Novo e velho aqui são termos pouco precisos que têm sido expressos por rótulos mais articulados como foco e pressuposição, comentário e tópico, rema e tema. Não é nosso objetivo aqui discutir os contornos precisos de cada um desses pares de conceitos, mas apenas ficar com a intuição básica, e teoricamente bastante difundida, de que um enunciado linguístico distingue, por meio da prosódia e da ordem de palavras, conteúdos novos de conteúdos mutuamente compartilhados. Uma abordagem que dá expressão a essa ideia é a encontrada em Roberts (2012), por exemplo, e conhecida como abordagem de Questions under Discussion (QUD), segundo a qual todo enunciado responde a uma questão, implícita ou explícita. É o conteúdo dessa questão que determina, entre outras coisas, certas escolhas prosódicas dos

${ }^{9}$ Um conteúdo pode ser compartilhado, mas não mutuamente compartilhado. Uma pessoa pode saber de um acontecimento, por exemplo, mas não ter consciência de que outra pessoa saiba o mesmo. Nesse caso, as duas sabem de algo (compartilham o conteúdo), mas não compartilham o conteúdo mutuamente, já que uma não sabe que a outra sabe o mesmo. O compartilhamento mútuo de conteúdos, mesmo em sua formulação mais atenuada (cf. Sperber \& Wilson 1996) é essencial para a realização de uma série de inferências pragmáticas. 
falantes, como o constituinte da sentença que deve receber destaque acentual. Não é por outra razão que o enunciado (4a) funciona como uma resposta adequada à questão (5a) e o (4b) funciona como uma resposta adequada à questão (5b). $\mathrm{O}$ contrário, no entanto, não é verdadeiro ${ }^{10}$.

(4a) O João beijou a MARIA.

(4b) O JOÃO beijou a Maria.

(5a) Quem o João beijou?

(5b) Quem beijou a Maria?

Adotando uma nomenclatura bastante difundida, vamos dizer que, em (4a), “O João beijou alguém” é uma pressuposição, ou seja, conteúdo mutuamente compartilhado, e que, nesse mesmo enunciado, a informação de que a pessoa beijada foi a Maria é a informação focal (nova) ${ }^{11}$. Já em (4b) "alguém beijou a Maria" é pressuposto, e a informação de que essa pessoa seja o João é informação focal. Há enunciados, contudo, que apresentam apenas informação nova, ou seja, enunciados em que todo o conteúdo é novo. É o que se percebe no diálogo (6).

(6) A: Tô achando o João tão feliz hoje. O que será que houve?

B: O João beijou a Maria.

Em (6), nada está pressuposto pelo segundo enunciado do falante B. Estamos aqui diante de um tipo de sentença que Vallduvi (1993) chama de sentença all focus. Sentenças de foco integral são aquelas cujo conteúdo é totalmente novo. Elas respondem a uma questão do tipo "O que houve?", em um contexto out of the blue.

Defendemos, neste trabalho, a ideia de que enunciados de dupla negação, por sua estruturação formal, apresentam um conteúdo sentencial integralmente novo e, ao mesmo tempo, integralmente pressuposto. É desse conflito que surge a impressão de ativação: o que não é novo nem pressuposto é ativado. O que produz esse efeito de processamento é justamente a forma da sentença de dupla negação, com o conteúdo integral da sentença topicalizado à esquerda de uma negação em fim de frase. Ou seja, é a sinalização de que o mesmo conteúdo é pressuposto (pelo que é topicalizado) e é novo (pela utilização da negação em posição de foco). No caso dos sujeitos anafóricos que investigamos aqui, o resultado disso é um favorecimento do sujeito nulo, como veremos a seguir - algo de certa forma "inesperado" em PB, uma língua que vem historicamente favorecendo sujeitos foneticamente expressos.

Por veicularem a ideia de ativação, estruturas de dupla negação prestamse a realizar duas funções pragmáticas encontradas em dados da Região Sul do Brasil, conforme Goldnadel (2016) e Goldnadel \& Petry (2017). Ambos os

\footnotetext{
${ }^{10}$ Os exemplos (4) a (6) foram criados por nós para ilustrar o ponto em discussão.

${ }^{11} \mathrm{O}$ leitor interessado em uma representação pragmática formal mais detalhada desses elementos encontra boa fonte em Lambrecht (1994).
} 
trabalhos identificam enunciados de dupla negação instanciando as funções de denegação e de retorno a tópico quantitativo. No primeiro caso, trata-se de produzir um enunciado negativo para impedir a aceitação de algum conteúdo proferido ou sugerido pelo interlocutor ou pelo próprio falante em manifestação prévia. O exemplo a seguir é um caso em que uma participante de uma entrevista sociolinguística, ao mostrar um álbum de fotografias, procurando identificar cada uma das pessoas ali retratadas, usa um enunciado de dupla negação para rejeitar uma afirmação própria feita um pouco antes.

(7) F: Ih! A praia sim. Isso aqui eu nem sei o que que é. Se é uma mulher se enforcando na árvore. O que que é?

E : Não, está com três crianças.

I: O que que está escrito aqui? A senhora quer trocar a letra!

F: Olhe como é que eu estou de cabeça baixa. Quer ver. Ah, mas essa aí é a N. Y.

I: Que nome bobo é esse!

F: Não, essa não é a N., não. Essa aí é a D. Eu acho que é o telefone de alguém que eu peguei e pus aí atrás, tá! Essa aqui é uma sobrinha que já é morta. E essa, amiga dela.

E : Nossa! Que bonita que ela era.

Os casos de retorno a tópico quantitativo são aqueles em que o falante, tendo se afastado da resposta a um tópico quantitativo (que pode ser entendido como uma QUD) pela utilização de enunciados que respondem a questões criadas por tópicos qualitativos ${ }^{12}$, pretende sinalizar a volta à questão quantitativa central.

(8) E: Você gostaria de sair de Curitiba, ou você sairia se você precisasse se mudar ou você preferiria ficar morando aqui?

F: Bom, eu, se tivesse que ir, né? Fazer o que? Mas eu acho que não. Se for mudar mas pra um outro bairro assim, mas ficam em Curitiba. Eu já conheci a cidade de São Francisco, eu fui pra Santo Ângelo, Florianópolis, outras cidades assim. Mas você vai só a passeio. Eu acho que pra morar não. (...)

$\mathrm{E}$ : Por que que você não gostou dessas cidades e gosta mais de Curitiba?

F: Eu não sei se é porque a gente foi criado aqui, né? Então, às vezes, a gente você vê: está úmido, de repente de manhã você sai está frio, está quente, está chovendo. Cidadezinha, né? Que todo mundo reclama. E se você vai num outro lugar, se é frio é frio, se é quente é quente, se chove só chove, né? Mas eu acho que a gente já está acostumado a levar sombrinha, a blusa e sabe? Então acho que eu não sairia não. Eu acho que acostumo aqui mesmo.

12 O leitor interessado encontra a distinção entre tópico quantitativo, tópico qualitativo, comentário quantitativo e comentário qualitativo em van Kuppevelt (1995a, 1995b, 1996). 
Em (8), a questão posta pelo entrevistador indaga sobre a possibilidade de o entrevistado mudar-se de Curitiba. Há uma primeira resposta quando o entrevistado afirma "Mas acho que não". O entrevistador, contudo, insiste na pergunta indagando motivos para a indisposição do entrevistado para mudar de cidade. Segue-se a essa pergunta uma exposição de razões para a opinião inicial. Entendendo que esses motivos são subsidiários à pergunta anterior, o entrevistado usa a dupla negação, promovendo um retorno à questão anterior (QUD), ou seja, a um tópico sentencial quantitativo anterior.

Tanto a denegação quanto o retorno a tópico prévio retomam conteúdo ativado. Dizer que um conteúdo está ativado é o mesmo que reconhecer que está bastante acessível, sendo propício, portanto, a apagamentos. Sabe-se que, entre todos os constituintes de uma sentença, o sujeito em posição inicial é um constituinte saliente do ponto de vista discursivo (a literatura sobre o assunto é vasta, talvez Pontes 1986, 1987 sejam os trabalhos pioneiros a discutir de maneira sistemática a relação entre a "função sintática" sujeito gramatical e a "função informacional" tópico discursivo em PB). Nas próximas seções deste artigo, defendemos a ideia de que enunciados de dupla negação, mesmo sendo bastante propícios a apagamentos (por expressarem conteúdo ativado), podem ocorrer com ou sem sujeito pronominal expresso. Essa opção, no entanto, não é totalmente livre, estando sujeita a injunções de outras ordens a serem elucidadas a seguir.

\section{A DUPLA NEGAÇÃO E A OCORRÊNCIA DE SUJEITO}

A literatura tem mostrado, desde a década de 1990, pelo menos, que o PB já não exibe características de uma língua + pro-drop canônica, que favorece sujeitos foneticamente nulos - diferentemente do português europeu, por exemplo (cf. Duarte 1993, 1995, Duarte, Kato \& Barbosa, 2001, Cavalcante \& Duarte 2008, Duarte \& Figueiredo Silva 2016, entre outros). Diversos estudos diacrônicos (em que se comparam dados do próprio PB, em diferentes sincronias), como sincrônico-comparativos (em que se comparam dados do PB com dados de línguas tipicamente + pro-drop - como o espanhol ou o italiano - e com línguas tipicamente -pro-drop, como o inglês ou o francês) têm mostrado isso, pelo menos desde os trabalhos pioneiros de Duarte (1989, 1993); cf. também Duarte (1995, 2003), Figueiredo Silva (1996), Kato (1999), Buthers (2009), Buthers \& Duarte (2012), Kato \& Duarte (2014), Duarte \& Figueiredo Silva (2016), Othero \& Spinelli (2019), entre tantos outros.

Podemos entender a gramática de uma língua como um sistema adaptativo complexo (cf. Haag 2016), e diferentes forças estão constantemente atuando em fenômenos gramaticais que estão inter-relacionados. Em nossa investigação, estamos analisando dois fenômenos aparentemente diversos (as estruturas de dupla negação e a ocorrência de sujeitos pronominais nulos e expressos nessas construções). Tentaremos justamente mostrar a relação entre esses dois fenômenos. Ambos vêm sendo atestados recentemente em PB e podem ter zonas de intersecção. Como afirmam Martins, Coelho \& Cavalcanti (2015: 223), “(...) 
uma mudança, em geral, está relacionada a outra mudança ou mudanças, como se fossem reações em cadeia. (...) entender qual é a natureza desse encaixamento é também entender o sistema linguístico dos fenômenos que estão em variação e mudança em determinada língua". Investigaremos, a partir daqui, quatro hipóteses que relacionam as orações com dupla negação e a presença ou ausência de sujeitos pronominais.

Nossa primeira hipótese de trabalho é, portanto, a seguinte:

I. Nas estruturas de dupla negação encontraremos mais sujeitos nulos do que sujeitos expressos.

Se construções com dupla negação favorecem a não expressão de conteúdos ativados, como é o caso com o sujeito, podemos supor que encontramos aí um contexto que favoreça o sujeito nulo.

Após analisarmos todas as orações com dupla negação que encontramos no corpus, confirmamos a Hipótese I, uma vez que encontramos mais ocorrências de construções de dupla negação com sujeito nulo (62 ocorrências) do que com sujeito preenchido (23 ocorrências), como apresentamos na tabela 1 .

\begin{tabular}{|l|c|c|}
\hline \multicolumn{3}{|c|}{ Sujeitos } \\
\hline Nulos & $\mathbf{6 2 / 8 5}$ & $\mathbf{7 3 \%}$ \\
\hline Preenchidos & $23 / 85$ & $27 \%$ \\
\hline
\end{tabular}

Tabela 1: Ocorrências de sujeitos pronominais nulos e expressos.

Das 85 ocorrências, $73 \%$ foram construções de dupla negação em que o sujeito não era foneticamente expresso (exemplo 9), ao passo que apenas pouco mais de um quarto das ocorrências continha um sujeito pronominal expresso (exemplo 10).

(9) E: Tem uma pracinha ali em cima que eles fizeram. Era um...

F: Ø Não é do meu tempo não.

(10) Eu estou achando que ele não vai aguentar a ponta não.

Entre as ocorrências que investigamos, notamos um padrão interessante: todas as ocorrências de sujeitos que retomavam proposições (tivemos apenas 10 ocorrências, ou seja, 11,7\% do total de ocorrências de dupla negação) foram retomadas por um sujeito nulo, como vemos no exemplo (11).

(11) (...) como ele já fez o pré o ano passado, então ele já tinha uma vaga mais ou menos garantida, né? No Leopoldina. E aí ele já está ali, já fez matrícula, já vai começar daqui a pouco. Ø Não foi difícil não. 
Esse é um fato interessante, porque isso também já foi atestado na história de outro fenômeno gramatical caro aos estudos sintáticos diacrônicos em PB: o fenômeno do objeto nulo (cf. Cyrino 1993, 1994/1997, por exemplo). Tal como o sujeito preenchido vem se tornando, diacronicamente, uma característica do $\mathrm{PB}$, a retomada anafórica de objeto direto vem deixando de ser realizada por um pronome clítico para ser realizada por um elemento vazio ou por um pronome tônico, em alguns casos (cf. Othero, Cyrino et al. 2018, por exemplo). Sujeito e objeto em PB parecem, portanto, estar seguindo um caminho inverso, a saber: o sujeito pronominal expresso está mais frequente do que em momentos anteriores do português (em que o sujeito nulo era o padrão, cf. referências já citadas), ao passo que o objeto pronominal expresso está menos frequente do que em momentos anteriores, cedendo lugar ao objeto nulo (cf. Cyrino 1994/1997, entre outros). Esse fato, na verdade, já havia sido constatado por Tarallo (1983) e Oliveira (1989), por exemplo.

Ora, o primeiro tipo de objeto direto anafórico que perdeu o clítico e favoreceu o objeto nulo em PB foi justamente o objeto direto que retomava proposições. Como atesta Cyrino (1994/1997: 15-16): “(...) pude observar que, dos clíticos que desapareceram no PB, o primeiro a 'cair' é o clítico neutro, ou seja, o clítico usado para 'substituir' uma oração".

O referente proposicional favorece, portanto, a retomada anafórica por objeto nulo em PB - e, nos nossos dados, favorece a retomada por sujeito nulo em construções de dupla negação. Imaginamos que esses dois fenômenos estejam relacionados aqui: ou seja, as mesmas características do referente (nesse caso, um referente proposicional) podem servir de gatilho para a retomada por um elemento foneticamente vazio, tanto no caso do objeto direto anafórico como no caso do sujeito anafórico (ao menos em construções de dupla negação).

Apesar de a dupla negação favorecer o sujeito nulo (é o que buscamos mostrar com a hipótese I), ainda encontramos cerca de 1/4 das ocorrências como casos de sujeito preenchido (27\%). Nenhuma dessas ocorrências, entretanto, tinha uma oração \proposição como antecedente, como vimos. Por isso, decidimos investigar justamente aquelas ocorrências que, contrariando a hipótese I, favoreceram o sujeito pronominal expresso. Ainda mantendo um olho no fenômeno do objeto nulo, investigamos quais tipos de sujeito poderiam estar aparecendo expressos nas construções de dupla negação. Elaboramos, então, a Hipótese II:

\section{Entre os sujeitos preenchidos, encontraremos preferencialmente antecedentes com o gênero semântico expresso (i.e., com o traço $+g s$ ).}

Diversos trabalhos têm mostrado, desde Cyrino, Duarte \& Kato (2000), que "quanto mais referencial é o sujeito maior a expectativa de um pronome expresso. (...) tomando-se a referencialidade como uma propriedade gradiente do mais específico para o menos específico, sendo os menos específicos aqueles itens não dotados do traço [+humano]" (Kato \& Duarte, 2014: 17).

Contudo, Creus \& Menuzzi (2004) propuseram a chamada "hipótese do gênero semântico", que estaria atuando no condicionamento de pronomes plenos 
e elementos vazios na função de objeto direto anafórico em PB. Ao contrário de grande parte da literatura sobre o objeto nulo em PB (como Cyrino 1994/1997, 2003, Schwenter, 2006, 2014, Casagrande 2012, entre outros), que considera relevantes os traços de animacidade e especificidade do antecedente no condicionamento para a retomada anafórica pronominal ou com elemento foneticamente nulo em função de objeto direto, Creus \& Menuzzi (2004: 150) entendem que "os efeitos dos traços de animacidade e especificidade (...) podem ser preditos por uma oposição única: a oposição entre os antecedentes que possuem e os que não possuem gênero semântico". Sua hipótese é que, se o antecedente não tiver gênero semântico aparente, será retomado por um objeto nulo; caso contrário, será retomado por um pronome pleno. Essa hipótese foi recentemente testada e confrontada com a hipótese clássica que envolve os traços de animacidade e especificidade do referente e tem se mostrado bem sucedida no estudo do objeto nulo em PB (cf. Pivetta, 2015, Ayres, 2016, Othero et al. 2016).

Nas palavras de Creus \& Menuzzi (2004: 161),

\begin{abstract}
a hipótese que associa os pronomes plenos do $\mathrm{PB}$ à presença de gênero semântico, e objetos nulos à ausência de gênero semântico é mais natural que a hipótese análoga baseada na distinção de animacidade: afinal, a diferença básica entre as formas ele/ela e os objetos nulos é que as primeiras portam especificações de gênero, enquanto que os últimos são justamente não-especificados para gênero (bem como para número, mas nisso os ONs [objetos nulos] não diferem significativamente dos PrPls [pronomes plenos], já que os últimos podem ou não portar a flexão de número). Ou seja, a escolha entre ONs e PrPls resultaria, basicamente, de um processo de concordância entre antecedente e forma anafórica: antecedentes com gênero semântico favorecem o uso de PrPls porque estas são as formas anafóricas especificadas para gênero; e antecedentes sem gênero semântico favorecem o uso de ONs precisamente porque ONs não possuem especificação para gênero semântico.
\end{abstract}

Em outras palavras, antecedentes com gênero semântico expresso tendem a ser retomados por pronomes. ${ }^{13}$ Acreditamos, seguindo Othero \& Spinelli (2019), que a hipótese do gênero semântico também pode se aplicar ao fenômeno do sujeito nulo (versus sujeito pronominal expresso). Verificaremos, então, se, entre os sujeitos pronominais expressos, predominam antecedentes com traço de gênero semântico marcado. A ideia básica de nossa investigação continua sendo expressa pela hipótese I: acreditamos que as construções de dupla negação favorecem o sujeito nulo (de fato, como mostramos na tabela 1, esse parece ser o caso). Entretanto, verificamos também os sujeitos pronominais nulos e preenchidos com relação ao traço de gênero semântico de seu antecedente.

Repare que há aqui um conflito entre esses dois princípios atuantes na gramática da língua - o primeiro relacionado à hipótese I e o segundo relacionado à hipótese II: por um lado, vimos que a construção de dupla negação favorece orações com sujeito pronominal nulo; por outro lado, o traço de gênero semântico

${ }^{13}$ Não nos aprofundaremos na hipótese do gênero semântico ou em suas motivações, por não ser esse o escopo de nosso trabalho - aqui apenas iremos aplicá-la aos dados de dupla negação com sujeito expresso e nulo. Remetemos o leitor a Creus \& Menuzzi (2004), Pivetta (2015) e Othero et al. (2016) para aprofundamentos dessa hipótese. 
do antecedente parece condicionar sua retomada anafórica por pronome expresso. Ambos os princípios estão atuando simultaneamente e em conflito.

Hipótese I: Dupla negação $\rightarrow$ favorece o sujeito nulo

\section{Hipótese II: Antecedente $+g s \rightarrow$ favorece sujeito pronominal expresso}

Figura 2: Princípios gramaticais em conflito.

O que acontecerá quando tivermos sujeitos anafóricos que retomam antecedentes ou apontam para referentes com o traço + gs nessas orações com dupla negação? Por um lado, o sujeito pronominal expresso é favorecido; por outro, o sujeito nulo o é. Antes de explicarmos como se dá a resolução deste conflito, temos, na verdade, de verificar se a Hipótese II será ou não confirmada empiricamente. Para isso, reanalisamos todos os sujeitos preenchidos que encontramos (24 ocorrências) e classificamos seus antecedentes conforme o traço de gênero semântico. Se a hipótese estiver correta, devemos encontrar preferencialmente referentes com gênero semântico marcado $(+g s)$ nas ocorrências de sujeitos pronominais expressos. Encontramos os seguintes resultados:

\begin{tabular}{|l|c|c|}
\hline \multicolumn{3}{|c|}{ Sujeitos expressos } \\
\hline$+\mathrm{gs}$ & $23 / 24$ & $95,8 \%$ \\
\hline -gs & $1 / 24$ & $4,2 \%$ \\
\hline
\end{tabular}

Tabela 2: Ocorrências de sujeitos expressos e o traço semântico de seus antecedentes.

De fato, confirmando a Hipótese II, verificamos que quase a totalidade das ocorrências com sujeitos pronominais expressos (23 de 24 ocorrências) são de sujeitos anafóricos ou exofóricos que retomam antecedentes ou apontam para referentes com o traço $+\mathrm{gs}$, sejam sujeitos de $1^{\mathrm{a}}$ ou $3^{\mathrm{a}}$ pessoa, como vemos nestes exemplos ${ }^{14}$ :

(12) Mas eu não sou fanático não.

(13) E: Tem que sair com [a mãe $]_{\mathrm{i}}$ de vez em quando. A mãe que sai sozinha ainda.

F: Uma vez eu fui de atrás dela. Uma vez eu fui atrás dela. Não, mas nunca mais ela quis me levar, né?

I: É chato, né? A gente ir em baile com filho.

F: Mas uma vez eu fui com ela, né? Mas a mãe nem dançar não dançava.

I: Agora não está dando para mulher dançar mais.

I: Quando eu ficar velha, que eu não puder dançar, daí eu vou, né? Porque aí não dá pra dançar.

${ }^{14}$ Encontramos um único caso de sujeito de $2^{\mathrm{a}}$ pessoa. Interessantemente, foi um sujeito nulo, com um antecedente você genérico (-gs, portanto): Pessoa tinha que sofrer um pouco, às vezes, na mão do pai dela, na mãe dela. Nem espiava. Aquilo precisava [você $]_{i}$ entrar na simpatia deles, senão $\varnothing_{\mathrm{i}}$ não ia não. Então, isso se tornava gostoso. 
E: Ela não trouxe de vara, não? Ela não trouxe de vara, de chinelo para casa não?

No exemplo (12), vemos o pronome de $1^{\mathrm{a}}$ pessoa do singular (eu), exofórico, que faz referência ao falante, um referente com gênero semântico identificado $(+\mathrm{gs})$, portanto. Em (13), temos um pronome de $3^{\mathrm{a}}$ pessoa do singular (ela), anafórico, que retoma o antecedente [a mãe], um DP com gênero semântico também expresso $(+\mathrm{gs})$.

Recapitulando: até aqui, elaboramos duas hipóteses que dizem respeito ao sujeito nas estruturas de dupla negação e que parecem ter sido confirmadas.

I. Nas estruturas de dupla negação encontraremos mais sujeitos nulos do que sujeitos expressos. Encontramos 71,25\% de sujeitos nulos entre as ocorrências.

II. Entre os sujeitos preenchidos, encontraremos preferencialmente antecedentes com o gênero semântico expresso (i.e., com o traço $+g s$ ). Entre os sujeitos preenchidos, 95,8\% retomam antecedentes + gs.

Ambas as hipóteses encontraram, portanto, respaldo empírico nos dados. Contudo, temos agora de pensar sobre como o conflito entre esses dois princípios (que ilustramos na Figura 2) pode ser resolvido. Dito de outra forma: há dois "princípios" gramaticais que estão em concorrência na gramática do PB no que tange à marcação de sujeito pronominal nas estruturas de dupla negação: o primeiro favorece sujeitos nulos (algo como em estruturas de dupla negação, o sujeito anafórico não precisa ser expresso, por ser um elemento altamente ativado na cadeia informacional discursiva); o segundo, ao contrário, favorece sujeitos expressos pronominalmente (algo como os sujeitos com o traço semântico + gs devem ser expressos foneticamente por um pronome). O segundo princípio é geral (fala sobre a marcação de sujeito pronominal na língua); o primeiro é específico (diz respeito apenas às estruturas de dupla negação). Temos aqui, portanto, um conflito que pode ser resolvido com a conhecida condição de Elsewhere ou "princípio de Pānini” (cf. Anderson, 1969, Kiparsky, 1973, Aronoff 1976). Ou seja: uma regra mais específica se aplica antes de uma mais geral. O princípio mais específico é o que está relacionado à estrutura da dupla negação; portanto, devemos encontrar mais sujeitos nulos do que preenchidos (e de fato encontramos). O princípio mais geral afirma que um antecedente $+\mathrm{gs}$ deve preferencialmente ser retomado por um sujeito pronominal expresso em qualquer tipo de oração (e não apenas nas orações com dupla negação; de fato, o traço semântico de gênero semântico do referente favoreceu o preenchimento de sujeito - 95,8\% dos antecedentes $+\mathrm{gs}$ foram retomados por sujeito expresso, como vimos).

Se nosso raciocínio estiver correto até aqui, podemos testar, então, mais duas hipóteses:

III. Entre os referentes com gênero semântico não identificado (-gs), encontraremos preferencialmente retomadas anafóricas com sujeitos nulos. 
IV. Entre os referentes com gênero semântico identificado (+gs), devemos encontrar variação livre entre sujeitos pronominais expressos e nulos.

Essas duas últimas hipóteses lidam com cenários bem distintos. A Hipótese III afirma que, em não tendo o conflito antecedente + gs versus dupla negação, devemos encontrar preferencialmente sujeitos nulos nas estruturas de dupla negação. Em outras palavras, se a hipótese I estiver de fato correta, devemos encontrar sujeitos nulos entre os referentes -gs; ou seja, a Hipótese III deve ser confirmada. Afinal, estamos tirando o "ruído" da equação aqui. Se a Hipótese III for confirmada, por acarretamento, a Hipótese I também será confirmada.

Eis o que encontramos entre os sujeitos em estruturas de dupla negação que retomam referentes que não apresentam gênero semântico expresso:

\begin{tabular}{|l|c|c|}
\hline \multicolumn{3}{|c|}{ Sujeitos que retomam referentes -gs } \\
\hline Nulo & $39 / 40$ & $97,5 \%$ \\
\hline Expresso & $1 / 40$ & $2,5 \%$ \\
\hline
\end{tabular}

Tabela 4: Ocorrências de sujeitos retomando referentes com o traço -gs.

De fato, tirando os referentes +gs da comparação, a dupla negação favorece maciçamente o sujeito nulo: 97,5\% das construções de dupla negação em orações com sujeitos que retomam referentes - gs aparecem com sujeito nulo.

Entretanto, a hipótese poderia estar equivocada e os resultados enviesados: seria possível pensar que a simples ausência de referentes $+g s$ poderia estar favorecendo o sujeito nulo nas construções de dupla negação, i.e. o condicionamento do sujeito nulo versus sujeito expresso poderia ser interpretado como sendo resultado exclusivo do traço de gênero semântico do referentel antecedente, de maneira completamente independente da construção de dupla negação. Por isso, postulamos também a Hipótese IV. Essa hipótese afirma que, entre os antecedentes com gênero semântico expresso $(+\mathrm{gs})$, devemos encontrar justamente um conflito entre os dois princípios. Ou seja, as 45 ocorrências de sujeitos que retomam antecedentes com gênero semântico expresso devem estar divididas entre a retomada pronominal expressa e a retomada por um sujeito nulo. Afinal, por um lado, como vimos, a construção de dupla negação favorece sujeitos nulos (vide a confirmação das Hipóteses I e III). Por outro lado, os referentes + gs estão diretamente relacionados à retomada por sujeito pronominal expresso (vide a confirmação da Hipótese II). Por isso, imaginamos encontrar variação livre nos casos em que há um conflito direto entre os dois princípios ${ }^{15}$. E eis o que encontramos:

${ }^{15}$ Os dados da Tabela 4 expressam a ausência de conflito: apenas ocorrências de sujeitos com antecedentes - gs em estruturas de dupla negação. Na Tabela 5, ao contrário, apresentaremos os dados que encontramos em situação máxima de conflito: apenas ocorrência de sujeitos com antecedentes $+\mathrm{gs}$ em estruturas de dupla negação. 


\begin{tabular}{|l|c|c|}
\hline \multicolumn{3}{|c|}{ Sujeitos que retomam referentes $+\mathrm{gs}$} \\
\hline Expresso & $23 / 45$ & $51 \%$ \\
\hline Nulo & $22 / 45$ & $49 \%$ \\
\hline
\end{tabular}

Tabela 5: Ocorrências de sujeitos retomando referentes com o traço +gs.

Confirmando o que previmos na Hipótese IV, de fato há variação livre quando do conflito direto entre os dois princípios gramaticais que propusemos aqui. O que encontramos aqui vai contra o que postulam Cyrino, Duarte \& Kato (2000) e Kato \& Duarte (2014), por exemplo. Para elas, "quanto mais referencial, maior a possibilidade de um pronome não-nulo" (Kato \& Duarte 2014: 5). Aqui, entretanto, das 45 ocorrências de sujeitos altamente referenciais que encontramos ("referenciais" tanto para a hipótese de sujeitos thumanos, de $1^{\mathrm{a}}, 2^{\mathrm{a}}$ e $3^{\mathrm{a}}$ pessoas, como para a hipótese do gênero semântico - que tomamos emprestada e adaptamos de Creus \& Menuzzi 2004), metade deles (49\%) foi retomada por um sujeito nulo. Nós conseguimos explicar esse fato justamente através de nossas quatro hipóteses: as estruturas de dupla negação favorecem o sujeito nulo, mas esse princípio entra em conflito com o princípio gramatical da retomada pronominal expressa de sujeitos "referenciais" - i.e., de gênero semântico marcado (+gs).

\section{CONSIDERAÇÕES FINAIS}

Investigamos aqui a omissão e a expressão de sujeitos pronominais nulos e expressos em construções de dupla negação em PB. Analisamos, de maneira específica, um corpus de língua falada na região Sul do Brasil e constatamos que, apesar de a literatura apontar para o fato de que o PB, em geral, tem privilegiado orações com sujeito pronominal expresso em detrimento de sujeito nulo (cf. literatura mencionada ao longo do texto), percebemos que as construções de dupla negação favoreciam orações com sujeito nulo. Isso explica por que uma construção de dupla negação veicula conteúdos ativados discursivamente (que, por princípio, podem não ser expressos na superfície da frase). Além disso, investigamos a relação desse efeito pragmático com um fator semântico que favorece a retomada por sujeito pronominal expresso: o traço de gênero semântico do referente. $\mathrm{Na}$ seção anterior, analisamos cenários de confluência e conflito entre esses princípios gramaticais distintos e provamos que aquilo que encontramos na análise empírica do corpus corrobora o que havíamos previsto teoricamente.

De maneira específica: testamos quatro hipóteses sobre a presença versus ausência de sujeito pronominal expresso em estruturas de dupla negação.

I. Nas estruturas de dupla negação encontraremos mais sujeitos nulos do que sujeitos expressos (por questões de ativação pragmática). 
II. Entre os sujeitos preenchidos, encontraremos preferencialmente referentes $\backslash$ antecedentes com o gênero semântico identificado $(+\mathrm{gs})$.

III. Entre os referentes com gênero semântico não identificado (-gs), encontraremos preferencialmente sujeitos nulos.

IV. Entre os referentes $(+\mathrm{gs})$, devemos encontrar variação livre, já que haverá um conflito entre princípios distintos.

Todas essas hipóteses, como vimos na seção anterior, foram confirmadas empiricamente, o que parece corroborar a ideia de ativação discursiva nas estruturas de dupla negação em PB e a ideia de exponenciação pronominal de sujeitos que apontam ou retomam referentes cujo traço de gênero semântico é marcado.

\section{REFERENNCIAS}

ANDERSON, S. R. West Scandinavian vowel systems and the ordering of phonological rules. Tese de Doutorado. Massachusetts Institute of Technology, 1969.

ARONOFF, M. Word formation in generative grammar. Cambridge: MIT Press, 1976.

AYRES, M. R. Aspectos condicionadores do objeto nulo e do pronome pleno em português brasileiro: uma análise da fala infantil. Dissertação de Mestrado. Pontifícia Universidade Católica do Rio Grande do Sul, 2016.

BISOL, L.; MONARETTO, V. N. O. Prefácio: VARSUL e suas origens, uma história sumariada. ReVEL, edição especial n. 13, p. 6-11, 2016.

BUTHERS, C. M. Emergência da ordem [XP V (DP)] no Português Brasileiro Contemporâneo e o Parâmetro do Sujeito Nulo: uma abordagem minimalista. Belo Horizonte, Universidade Federal de Minas Gerais. Dissertação de Mestrado, 163f. 2009.

BUTHERS, C. M.; DUARTE, F. B. Português Brasileiro: uma língua de sujeito nulo ou de sujeito obrigatório?. Revista Diacrítica, v. 26, n. 1, 2012, p. 64-88.

CAMARgos, M. A negativa: uma análise qualitativa. Anais do V Congresso de Ciências Humanas, Letras e Artes, Centro de Artes e Convenções de Ouro Preto, 2001.

CASAGRANDE, S. Restrições de ocorrência do objeto direto anafórico no Português Brasileiro: gramática adulta e aquisição da linguagem. ReVEL, edição especial n. 6, p. 131-163, 2012.

CAVAlCANTE, S. R. O.; DUARTE, M. E. The subject position in Brazilian Portuguese: the embedding of a syntactic change. University of Pennsylvania Working Papers in Linguistics, v. 14, n. 2 , 2008, p. 54-62. 
COLLISCHONN, G.; MONARETTO, V. Banco de dados VARSUL: a relevância de suas características e a abrangência de seus resultados. ALFA: Revista de Linguística, v. 56, n. 3, p. 835-853, 2012.

CREUS, S; MENUZZI, S. O papel do gênero na alternância entre objeto nulo e pronome pleno em português brasileiro. Revista da ABRALIN, v. 3, n. 1-2, 2004.

CYRINO, S. M. L. O objeto nulo no português do Brasil: um estudo sintático-diacrônico. Tese de doutorado: Unicamp, 1994 (publicada em 1997 pela Ed. da Universidade Estadual de Londrina, Londrina, PR).

CYRINO, S. M. L. Observações sobre a mudança diacrônica no português do Brasil: objeto nulo e clíticos. In: ROBERTS, I.; KATO, M. A. (orgs.) Português brasileiro: uma viagem diacrônica. Campinas: Ed. da Unicamp, 1993, p. 163-185.

CYRINO, S. M. L.; DUARTE, M. E.; KATO, M. A. Visible subjects and invisible clitics in Brazilian Portuguese. In: KATO, M. A.; NEGRÃO, E. V. (eds.) Brazilian Portuguese and the Null Subject Parameter. Frankfurt: Vervuert-Iberoamericana, 2000, p. 55-104.

CYRINO, S. M. Para a história do português brasileiro: a presença do objeto nulo e a ausência dos clíticos. Letras de Hoje, v. 38, n. 1, 2003.

DAHL, O. 2001. Infl ationary eff ects in language and elsewhere. In: BYBEE, J.; HOPPER, P. Frequency and the emergence of linguistic structure. Amsterdam/Philadelphia: John Benjamins, 2001, 471-480.

DETGES, U.; WALTEREIT, R. Grammaticalization vs reanalysis: a semantic-pragmatic account of functional change in grammar. Zeitschrift fur Sprachwinssenchaft, 21.1, 2002, p. 151-195.

DUARTE, I.; FIGUEIREDO SILVA, M. C. The null subject parameter and the structure of the sentence in European and Brazilian Portuguese. In: WETZELS, L.; COSTA, J.; MENUZZI, S. M. The handbook of Portuguese Linguistics. West Sussex: Wiley Blackwell, 2016.

DUARTE, M. E. L. A evolução na representação do sujeito pronominal em dois tempos. In: PAIVA, M. C.; DUARTE, M. E. L. (orgs.) Mudança linguística em tempo real. Rio de Janeiro: Contra Capa, 2003, p. 115-128.

DUARTE, M. E. L. A perda do princípio "evite pronome" no português brasileiro. Campinas, Universidade Estadua de Campinas. Tese de Doutorado, 1995.

DUARTE, M. E. L. Clítico acusativo, pronome lexical e categoria vazia no português do Brasil. In: TARAllO, F., (org.) Fotografias sociolingüisticas. Campinas: Editora da Unicamp, 1989, p. 19-34.

DUARTE, M. E. L. Do pronome nulo ao pronome pleno: a trajetória do sujeito no português do Brasil. In: ROBERTS, I.; KATO, M. A. (Orgs.). Português brasileiro: uma viagem diacrônica. Campinas: Ed. da Unicamp, 1993. p. 107-125.

DUARTE, M. E. L. O sujeito em peças de teatro (1833-1992): estudos diacrônicos. São Paulo: Parábola Editorial, 2012.

DUARTE, M. E. Sociolinguística "Paramétrica". In: MOLLICA, M. C.; FERRAREZI JR., C. Sociolinguística, sociolinguísticas: uma introdução. São Paulo: Contexto, 2016, p. 33-44. 
FIGUEIREDO SILVA, M. C. A posição sujeito no Português Brasileiro - frases finitas e infinitivas. Campinas: Editora da Unicamp, 1996.

FURTADO DA CUNHA, M. A. Grammaticalization of the strategies of negation in Brazilian Portuguese. Journal of Pragmatics, Amsterdam, v. 39, 2007, p. 1638-53.

FURTADO DA CUNHA, M. A. Grammaticalization of the strategies of negation in Brazilian Portuguese. Journal of Pragmatics, 39, 2007, p. 1638-1653.

FURTADO DA CUNHA, M. A. O modelo das motivações competidoras no domínio funcional da negação. DELTA, 17, 2001, pp. 01-30.

FURTADO DA CUNHA, M. A. O modelo das motivações competidoras no domínio funcional da negação. DELTA 17, 2001, p. 01-30.

GIVÓN, T. Functional English Grammar. Cambridge: Cambridge University Press, 1996.

GOLDNADEL, M. Funções pragmáticas de enunciados de dupla negação: análise de dados de Curitiba. ReVEL, edição especial, no 13, 2016, pp. 144-180.

GOLDNADEL, M.; LIMA, L. S.; BREUNIG, G.; ESQUIVEL, N. A.; LUZ, J. P. Estratégias alternativas de negação sentencial na região sul do Brasil: análise da influência de fatores pragmáticos a partir de dados do projeto VARSUL. RELIN, vol. 21, n. 2, 2013, p. 35-74.

GOLDNADEL, M.; LIMA, L. S.; BREUNIG, G.; ESQUIVEL, N. A.; LUZ, J. P. Estratégias alternativas de negação sentencial na região sul do Brasil: análise da influência de fatores pragmáticos a partir de dados do projeto VARSUL. Rev. Est. Ling., v. 21, no 2, 2013, pp. 35-74.

GOLDNADEL, M.; PETRY, P. Função pragmática de retorno a tópico em enunciados de dupla negação: evidências a partir de dados da cidade de Curitiba. Cadernos de Estudos Linguísticos, no 59 (2), 2017 pp. 397-418.

HAAG, C. R. Editorial: Linguística e Sistemas Complexos. ReVEL, v. 14, n. 27, 2016, p. i-iii.

HANSEN, M. M. Reinforcers in old and middle french: a discourse-functional approach. In: HANSEN, M. M.; VISCONTI, J. Current trends in diachronic semantics and pragmatics. Bingley: Emerald Group Publishing Limited, 2009, p. 227-250.

HOEKSEMA, J. Jespersen recycled. In: VAN GELDEREN, E. Cyclical change. Amsterdam: John Benjamin, 2009, pp. 15-34.

HOEKSEMA, J. Jespersen recycled. In: VAN GELDEREN, E. Cyclical change. Amsterdam: John Benjamin, 2009, p. 15-34.

KATO, M. A. Strong pronouns and weak pronominals in the null subject parameter. Probus (Dordrecht), Berlin, v. 11, n 1, 1999, p. 1-37.

KATO, M. A.; DUARTE, M. E. Restrições na distribuição de sujeitos nulos no português brasileiro. Revista Veredas, v. 18, n. 1, 2014, p. 1-22.

KIPARSKY, P. "Elsewhere" in phonology. In: ANDERSON, S. R.; KIPARSKY, P. A festschrift for Morris Halle. Holt: Rinehart and Winston, 1973. p 93-106. 
KIPARSKY, P.; CONDORAVDI, C. Tracking Jespersen's cycle. In: JANSE, M.; JOSEPH, B.D.; RALLI, A. Proceedings of the 2nd International Conference of Modern Greek Dialects and Linguistic Theory. Mytilene: Doukas, 2006, p. 01-22.

LAMBRECHT, K. Information structure and sentence form: topic, focus, and the mental representations of discourse referents. Cambridge: CUP, 1994.

LARRIVÉE, P. The pragmatic motifs of the Jespersen cycle: Default, activation, and the history of negation in French. Lingua, 120, 2010, p 2240-2258.

LARRIVÉE, P. The role of pragmatics in grammatical change: The case of French preverbal non. Journal of Pragmatics, 43, 2011, p 1987-1996.

LIMA, S. L. Motivações pragmáticas para o surgimento de estruturas de dupla negação: uma análise a partir de dados da região Sul do Brasil. Instituto e Letras, Universidade Federal do Rio Grande do Sul - UFRGS. Dissertação de Mestrado, 110f. 2013.

MATTOSO CÂMARA J. R. Princípios de linguística geral. Rio de Janeiro: Padrão Livraria e Editora, 1977.

NUNES, L. L. Estrutura e funções pragmáticas da negação no sul do Brasil. Porto Alegre. Instituto e Letras, Universidade Federal do Rio Grande do Sul - UFRGS. Dissertação de Mestrado, 110f. 2017.

OLIVEIRA, D. P. O preenchimento, a supressão e a ordem do sujeito e do objeto em sentenças do português do Brasil: um estudo quantitativo. In: TARALLO, F. (org.) Fotografias sociolinguísticas. Campinas: Pontes, 1989.

OTHERO, G. A.; AYRES, M. R.; SCHWANKE, C.; SPINELLI, A. C. A relevância do traço gênero semântico na realização do objeto nulo em português brasileiro. Working Papers em Linguística v. 17(1), 2016.

OTHERO, G. A.; CYRINO, S.; SCHABBACH, G.; ROSITO, R.; ALVES, L. M. Objeto nulo e pronome pleno na retomada anafórica em PB: uma análise em corpora escritos com características de fala. Revista da Anpoll, v. 1, 2018.

OTHERO, G. A.; SCHWANKE, C. Retomadas anafóricas de objeto direto em português brasileiro escrito. Revista de Estudos da Linguagem (UFMG), v. 26, n. 1, 2018.

OTHERO, G. A.; SPINELLI, A. C. Sujeito pronominal expresso e nulo no começo do séc. XXI (e sua relação com o objeto nulo em PB).Domínios deLingu@gem, v. 13, n. 1, 2019.

PIVETTA, V. Objeto direto anafórico no português brasileiro: uma discussão sobre a importância dos traços semântico-pragmáticos - animacidade/especificidade vs. gênero semântico. Dissertação de mestrado. Universidade Federal do Rio Grade do Sul, 2015.

PONTES, E. O tópico no português do Brasil. Campinas: Pontes, 1987.

PONTES, E. Sujeito: da sintaxe ao discurso. São Paulo: Ática, 1986.

ROBERTS, C. Information structure in discourse: towards an integrated formal theory of pragmatics. Semantics and Pragmatics, v. 5, 2012, pp 1-69. 
RONCARAT I, C. A negação no português falado. In: MACEDO, A. T.; RONCARAT , C.; MOLLICA, M. C. Variação e discurso. Rio de Janeiro: Tempo Brasileiro, 1996, pp. 97-112.

SCHWEGLER, A. Predicate negation in contemporary Brazilian Portuguese: a change in progress. Orbis, Leuven, v. 34, p. 187-214, 1991.

SCHWENTER, S. A. Fine-Tuning Jespersen's Cycle. In: Birner, B.; Ward, G. Drawing the Boundaries of Meaning: Neo-Gricean Studies in Pragmatics and Semantics in Honor of Laurence R. Horn. Amsterdam: Benjamins, 2006, p. 327-344.

SCHWENTER, S. A. Fine-Tuning Jespersen's Cycle. In: BIRNER, B.; WARD, G. Drawing the Boundaries of Meaning: Neo-Gricean Studies in Pragmatics and Semantics in Honor of Laurence R. Horn. Amsterdam: Benjamins, 2006, pp. 327-344.

SCHWENTER, S. A. Null objects across South America. Selected proceedings of the 8th Hispanic Linguistics Symposium. Somerville: Cascadilla Press, 2006.

SCHWENTER, S. A. The pragmatics of negation in Brazilian Portuguese. Lingua, v. 115, 2005, pp. 1427-56.

SCHWENTER, S. A. The pragmatics of negation in Brazilian Portuguese. Lingua, Amsterdam, v. 115, p. 1427-56, 2005.

SCHWENTER, S. A. Two kinds of differential object marking in Portuguese and Spanish. PortugueseSpanish interfaces: Diachrony, synchrony, and contact, 2014.

SEIXAS, V. C.; ALKMIN, M. G. R. A negação sentencial em textos de autores brasileiros dos séculos XVIII e XIX: considerações sobre implementação, transição e origem da estrutura [NãoVNão]. Veredas, v. 17, no 2, 2013, p. 83-113.

SOUSA, L. T. A Gramaticalização do não no português brasileiro e a etapa do processo. Domínios de Lingu@gem, v. 1, n. 2, 2007, p. 1-17.

SOUZA, A. S.; LUCCHESI. D. Estruturas de negação em uma comunidade rural afro-brasileira. Hyperion, no 7, 2004.

TARALLO, F. Relativization strategies in Brazilian Portuguese. Tese de Doutorado. University of Pennsylvania, 1983.

VALLDUVI, E. The informational component. Tese de Doutorado. University of Pensilvania, 1993.

VAN DER AWERA, J. On the diachrony of negation. In: HORN, L. The expression of negation. New York: Walter de Gruyter, 2010, p. 73-109.

VAN DER AWERA, J. The Jespersen Cycles. In: VAN GELDEREN, E. Cyclical change. Amsterdam: John Benjamin, 2009. p. 35-71.

VAN DER AWERA, J. The Jespersen Cycles. In: VAN GELDEREN, E. Cyclical change. Amsterdam: John Benjamin, 2009, p. 35-71.

VAN KUPPEVELT , J. Main structure and side structure in discourse. Linguistics, 33, 1995b, pp. 809-833. 
VAN KUPPEVELT, J. Directionality in Discourse: Prominence Differences in Subordination Relations. Journal of Semantics, 13, 1996, pp. 363-395.

VAN KUPPEVELT, J. Discourse structure, topicality and question. Journal of Linguistics, 31, 1995a, pp. 109-147.

VOSSEN, F.; VAN DER AUWERA, J. The Jespersen cycles seen from Austronesian. In: HANSEN, M. B. M.; VISCONTI, J. The diachrony of negation. Amsterdam: John Benjamin, 2014, pp. 47-82.

Recebido: 4/3/2020

Aceito: 6/8/2020

Publicado: 24/8/2020

Cad. Est. Ling., Campinas, v.62, p. 1-21, e020011, 2020 